\title{
Smart Security System for Vehicles
}

\author{
Dr. Pramod Sharma ${ }^{1}$, Akash Shrivastav ${ }^{2}$, Vivek Parashar ${ }^{3}$, Okesh Kumar ${ }^{4}$, RamNaresh $^{\mathbf{5}}$ \\ Faculty, PG Dept. of ECE, R.B.S. Engineering \& Technical Campus, Bichpuri, Agra, India ${ }^{1}$ \\ B. Tech, Final Year Students, PG Dept. of ECE, R.B.S. Engineering \& Technical Campus, Bichpuri, Agra, India ${ }^{2,3,4,5}$
}

\begin{abstract}
In the designed system we can easily communicate with our vehicle from anywhere with the help of GSM and we can command our vehicle according to our need via message to avoid stealing of our vehicle. The existing security system is based on buzzer and is a single password system that cans we easily stolen. The designed system "Smart Security System for Vehicle" is based on OTP, being sent to the owner registered number, the owner has to enter the OTP to turn ON the ignition system, and the OTP is random so it can't be stolen by another person. If somehow OTP is cracked by someone than owner can easily stop the vehicle from anywhere with the help of mobile phone. Also, the vehicle owner can easily trace the location of his / her vehicle from anywhere with the help of GPS.
\end{abstract}

Keywords: GSM, GPS, 4x4 Keypad, Microcontroller, OTP

\section{INTRODUCTION}

Now day's automobile thefts are increasing at an alarming rate all over the world. So to escape vehicles from the thieves here, we are taken a project to develop "Smart Security System for Vehicle". The idea of this project comes from social responsibility towards society. Due to irresponsibility of the present security system, which is based on buzzer system and it can be easily removable by the theft. With the new inventions and advancement in technology in the field of electronics, the desire to live a better life is increasing day by day. The new technologies have emerged in almost every field like industries, medical, telecommunication, and aeronautics and now it has also entered in automobile. Apart from their busy any hectic schedule, human beings want to safeguard their vehicle by a click to button on a mobile phone. The new technologies and unique methodologies have tried to fulfil this wish of human beings to some extent by means of Smart Security System for Vehicle.

\section{Objectives of our Project Work}

The main objective of our project is to safeguard our vehicle against theft by incorporating the safety and security measures.

- $\quad$ The designed system should make the vehicles keyless.

- $\quad$ The designed system should have remote operated speed governor.

- $\quad$ One can easily turn off the engine i.e. ignition and fuel supply with the help of remote operated device.

- $\quad$ One can easily find the location of his / her vehicle.

\section{LITERATURE REVIEW}

The Vehicle Theft Protection Program was launched in late June 2007 by NICB, a not for profit organization dedicated to stopping vehicle theft. As part of the program, the organizations commissioned a national survey of 1,000 adults to determine areas where consumers needed the most education regarding vehicle theft protection. The on-line survey revealed that 67 percent of motorcycle owners who responded are at a high risk for theft.

\section{Following are the categories of vehicle theft}

Theft of an unattended vehicle without a key: The removal of a parked vehicle either by breaking and entry, followed by hotwiring or other tampering methods to start the vehicle, or else towing. In London, the police say that $50 \%$ of the annual 20,000 car thefts are now from high tech OBD (Onboard Diagnostic Port) key cloning kits (available online) and bypass immobilizer simulators.

Opportunistic theft: The removal of a vehicle that the owner or operator has left unattended with the keys visibly present, sometimes idling. Alternatively, some cars offered for sale are stolen during a "test drive". A "test drive" may also provide a potential thief with insight into where the vehicle keys are stored, so that the thief may return later to steal the vehicle. 
Carjacking: Refers to the taking of a vehicle by force or threat of force from its owner or operator. In most places, this is the most serious form of vehicle theft, since assault also occurs and the method of taking over the vehicle is essentially a robbery, a more serious form of theft.

Fraudulent theft: Illegal acquisition of a vehicle from a seller through fraudulent transfer of funds that the seller will ultimately not receive or through the use of a loan obtained under false pretenses. Many vehicles stolen via fraud are resold quickly thereafter. Using this approach, the thief can quietly evade detection and continue stealing vehicles in different jurisdictions. Car rental and Car dealership companies are also defrauded by car thieves into renting, selling, financing, or leasing them cars with fake identification, checks, and credit cards.

For finalizing objective of our project work we have reviewed following research papers majorly being related with the technology which we have used in our project work "Smart Security System for Vehicle", apart from books and websites.

- $\quad$ N.Pooja and G.V.S.Jyothirmayee [1] In this paper the author proposed a solution for misplacing keys or losing keys using fingerprint access to the vehicle. A fingerprint of every person is unique even identical twins don't have the same fingerprint.

- Archie O.Pachica and Dhave S.Barsalote [2] has showed how that user could view the current location of the motorcycle, shutdown the engine and capture an image of the thief. The software components are the mobile application which is the medium of communication of the user to the motorcycle and also serve as the main controller of the entire system.

- K.Sruthi and Mr.S.Ravi [3] describes that the development of a motorcycle security system which uses a microcontroller to detect theft and inform the owner using a mobile phone when theft occurs. This system protects motorcycle from theft and provides a reliable security system to motorcyclist with affordable price.

- K.Dinesh Kumar and B.Sasidharan [4] In their paper author present a bike security system using a password entered through keypad. This system turns on the buzzer when wrong password is entered for 3 times. User can change password using a keypad.

- Kompalli Supriya and M.Venkateshwarlu [5] describe the vehicle anti-theft system which consists of multiple layers of protection with one complementing the other, rather than the conventional anti-theft system where a particular system is only being used.

- Nitin Kumar and Jatin Agrawal [6] has developed a security system with a new feature included addition to the engine immobilizer and alarm i.e. alerting owner by SMS about the theft attempt, allowing user to control the system remotely by SMS.

- W.W.I.Wan Jusoh and K.A.MohdAnnuar [7] has create a model of motorcycle safety system using Radio Frequency Identification (RFID) and Global System of Communication (GSM) for controllable and improve safety on motorcycles.

\section{METHODOLOGY}

For our B. tech final year project work, we have taken up to design a much better and précised anti-theft cum vehicle tracking security system which would be commanded by the user itself from any where. In our project a microcontroller is used as the main control unit, which will integrate all the modules used in the system. Depending on the information being received by different modules it controls the whole system. The block diagram of the designed system is shown in Fig.1, which includes the following modules:

- GPS is known as Global Positioning System used to trace the location of vehicle. A GPS framework computes its position by accurately timing the signal sent by GPS satellites high over the Earth.GPS Receiver gets the location information from satellites. It consists of internal RTC back up and can be directly connected to USART of the microcontroller. The current date, time, longitude, altitude, speed, and travel direction/ heading among other data are provide by the module and can be used in many applications including navigation, fleet management, tracking system, mapping and robotics.

- GSM is known as Global System for Mobile Communication used for communication purpose. GSM module is basically used here for receiving of calls and for sending of confirmation message. Global system for mobiles (GSM) technology is used to establish cellular connection. It is used for transmitting mobile voice and data services. It contains everything needed to support the microcontroller.

- A microcontroller is a compact integrated circuit designed to govern a specific operation in an embedded system. A typical microcontroller includes a processor, memory and input/output (I/O) peripherals on a single chip.

- $\quad$ Keypad is used for entering the OTP. 
International Journal of Advanced Research in Computer and Communication Engineering

Vol. 8, Issue 4, April 2019

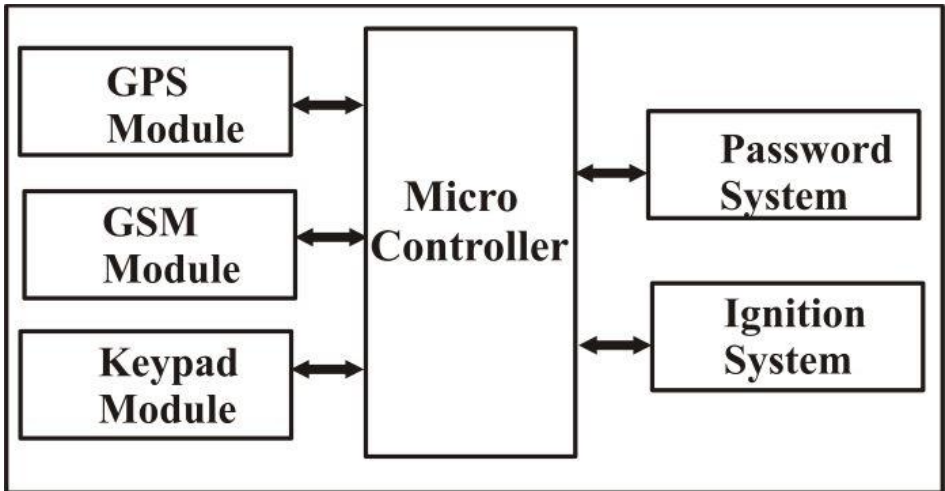

Fig.1. Block Diagram of Designed System.

\section{WORKING OF THE SYSTEM}

The working of the system can be summarized with the help of flow diagram as shown in Fig.2.

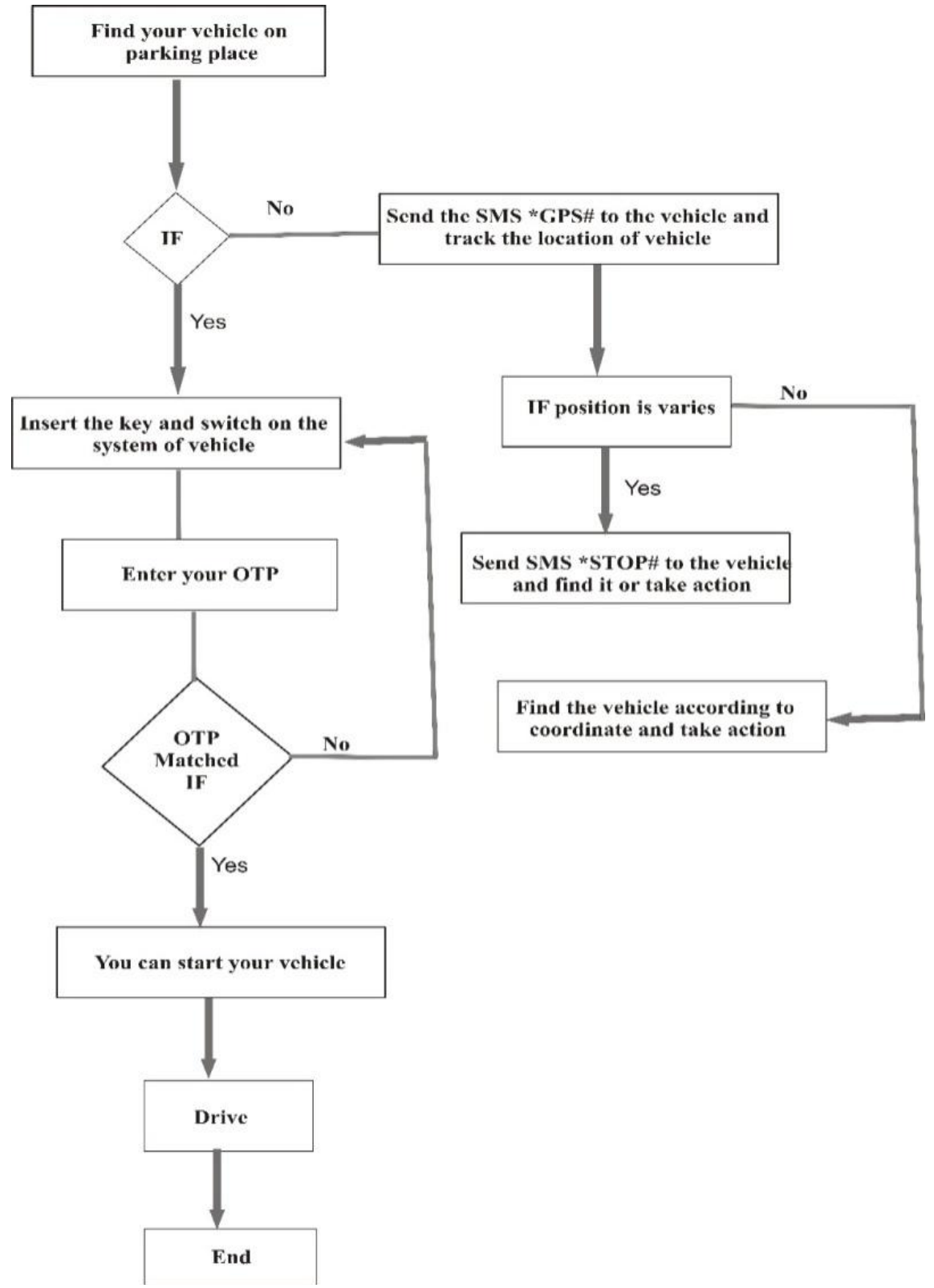

Fig. 2. Flow Diagram of Designed System 
As we turn on the system we get a random OTP with the help of GSM unit of system and which is generated by microcontroller, after entering the OTP with the use of keypad module which is read by password system. If the entered OTP is correct than only microcontroller turns ON the ignition system. Now, for tracing the location of vehicle, we have to send a message through registered number to the GSM module of system than microcontroller will send the coordinates of location along with google map link from GPS module in reply of command. Now to turn OFF the ignition system of vehicle, we have to send command through registered number to the GSM module of system than microcontroller turn OFF the ignition system with the help of relay.

\section{RESULT AND OBSERVATION}

\section{Result}

We have taken mainly three objectives for our project. All the objectives had been fulfilled successfully and thus we are able to design a fully secured system. The designed system is shown in Fig.3. Following are the outcomes of our project work :

- $\quad$ First is to make the vehicle keyless for which as we turn on the system, we get a random OTP after entering that OTP our ignition system will get turns on and there is also a message an LCD screen that "vehicle is ready for use.'In case if owner face difficulty due to discharge phone than there is one factory reset password feature by which owner can turns ON his/her vehicle easily.

- Second objective is to tracing the location of the vehicle. For this we have to send a command *GPS\# via message from the registered mobile number. As the designed system get to know this command it will send the coordinates of location along with google map link in reply of command.

- $\quad$ Third objective is to stop the vehicle. For this owner have to send the command *STOP\# via message from the registered mobile number. As the designed system get to know this command with the help of GSM to microcontroller, it turns OFF the ignition system with the help of relay.

Now there may be such condition takes place like the thief can remove the circuit from the vehicle so for this we had make a close loop system in which if the loop is not close than also the ignition system will not turn ON.

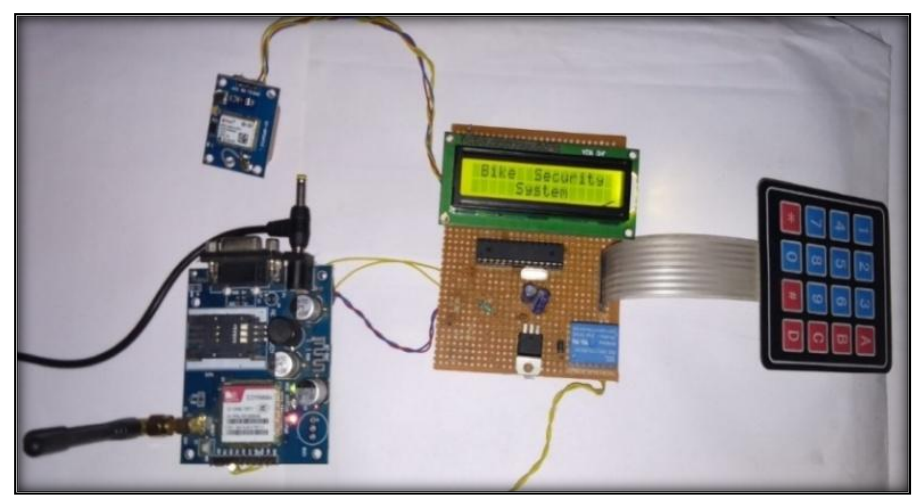

Fig. 3. Final Prototype of our Project

\section{Observation}

- As we turn ON the system it will show the message "Bike Security System" as shown in Fig.3. The system in the beginning takes around 1 minute to set GPS in a working condition and read out all the units which are connected with it. As the GPS comes in working condition it will send OTP to the owner's registered number.

- Now as the owner enters the received OTP to the system with help of keypad than the system first make the verification of that OTP, if the entered OTP is correct than it will turn ON the ignition system with the help of relay and the shows the message that vehicle started. If someone enters the wrong OTP than the whole system gets block.

- If some how the OTP number cracked by someone and the vehicle gets stolen than in that case the owner has to send a message *STOP\# with the help of registered mobile number to the vehicle's GSM. The message read by the microcontroller and turns OFF the ignition system immediately and the shows the message "Vehicle Stopped". As the ignition system is turned OFF and we want to know the location of vehicle for its collection, for this owner has to send a message *GPS\# which is read by microcontroller and it send the coordinates as well as a google map link via message to the registered owner's mobile number as shown in Fig. 4.

- To know the exact location of vehicle on google map owner has to click on google map link which is available in message. The exact location of vehicle will be displayed on mobile as shown in the last picture of Fig.4. 

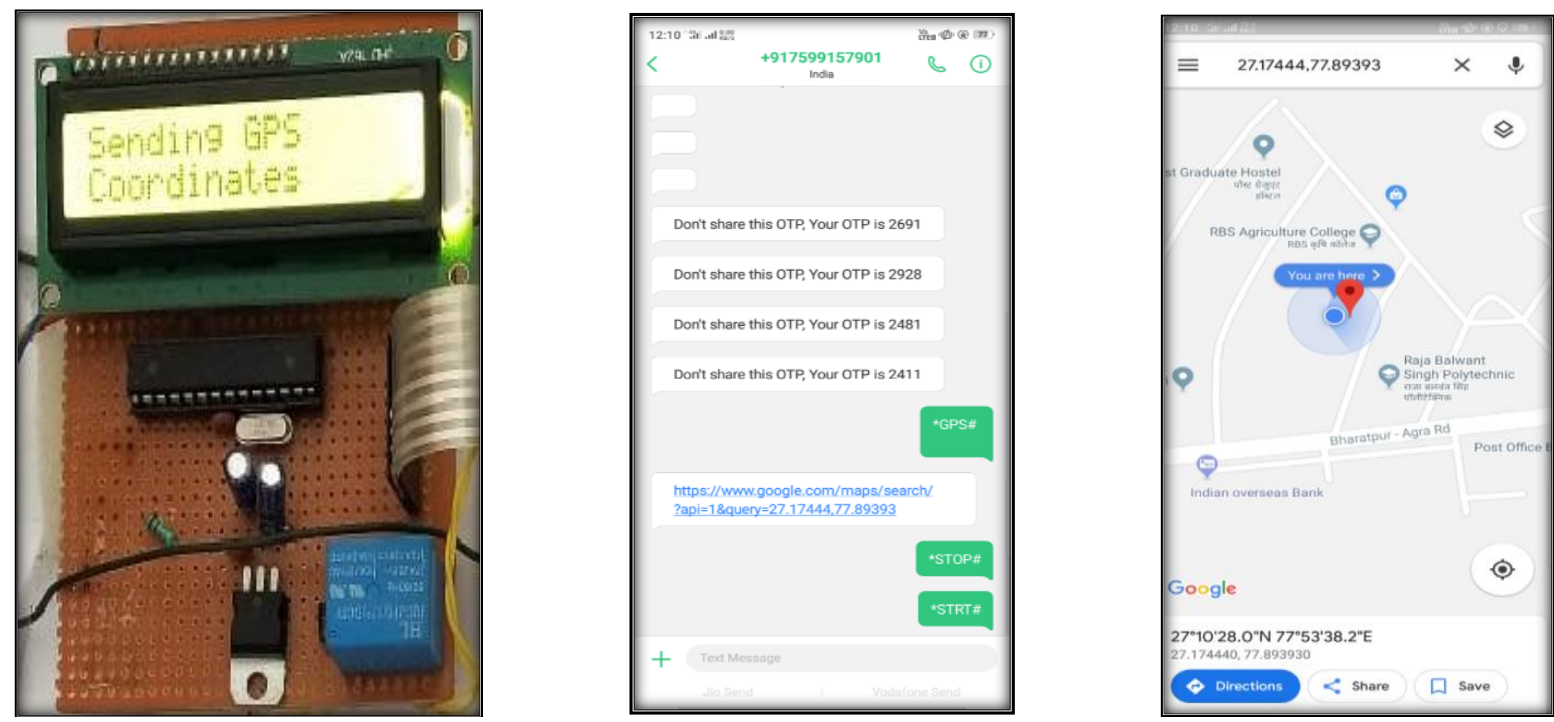

Fig. 4. Sending the Location with Coordinates as well as google map link in Mobile. Last picture shows the location of vehicle on Google Map.

\section{CONCLUSION}

In the designed system we can easily communicate with our vehicle from anywhere with the help of GSM and we can command our vehicle according to our need via message to avoid stealing of our vehicle. All the existing security system is based on buzzer and is a single password system that can be easily removable. In our project OTP is sent to the owner mobile number and the same OTP is used to turn ON the ignition system. The password generated is random so it can't be stolen by another person. If somehow the OTP password is cracked by someone than owner can easily stop the vehicle from anywhere with the help of registered mobile number. Also the vehicle owner can easily trace the location of vehicle from anywhere with the help of GPS. Finally we can say that a fully secured system for a vehicle has been designed by us and all the objectives taken has been fulfilled successfully.

\section{FUTURE SCOPE}

- Our project is particularly use to safeguard the vehicles. But by adding some more features we can make it use for cruise control system with the help of which we can easily make a certain limit on speed of vehicle from anywhere to avoid fatal accidents.

- For controlling of speed there is requirement of EFI system i.e. Electric Fuel Injector. EFI is a fuel injector system in which the flow of fuel is controlled by the electrical signal (amount of voltages). Thus by varying the voltage level, fuel flow can be varied and the speed can also be controlled easily.

- As the system takes some time to send OTP via message, so to minimize this delay we can use remote locking feature with our system. As user wants to go somewhere he can turn ON the system from a distance, by doing so, he gets the OTP in the mean time he reaches his / her vehicle, vehicle is ready for access.

\section{REFERENCES}

[1]. N.Pooja and G.V.S.Jyothirmayee " Fingerprint Based Anti-Theft System for Vehicle Safety.” International Journal of Innovative Research in Computer and Communication Engineering, vol. no.-5, Issue-2, February 2017.

[2]. Archie O.Pachica and Dhave S.Barsalote " Fingerprint Based Anti-Theft System for Vehicle Safety." International Journal of Applied Engineering Research, vol.12 pp. 2680-2687, November 11, 2017.

[3]. K.Sruthi, S.Ravi , Y.Kiran “ Anti-Theft Tracking System and Security System for Automobiles using GSM and ARM " IJEDR, Volume 4, Issue 12016.

[4]. K.Dinesh Kumar and B. Sasidharan “ Password Based Lock for Bike Security with Ignition Key Control System.” IJSART,volume 2, Issue 5, May 2016.

[5]. Kompalli Supriya and M.Venkateshwarlu "Anti Theft Control System Design Embedded System" International Journal of Advanced Technology and Innovative Research, vol.07, Issue.07, pp 1190-1193, July-2015.

[6]. Nitin Kumar and Jatin Aggarwal “Smart Bike Security System” International Journal of Education and Science Research, volume 2, Issue-2, April-2015.

[7]. W.W.I.Wan Jusoh and K.A.Mohd Annuar “ Motorcycle Security System using GSM and RFID” Journal of Advanced in Applied Mechanism, vol. 16, no. 1, pp. 1-9, 2015

[8]. https://en.wikipedia.org/wiki/Motor_vehicle_theft\#cite_note-UNDOC22. 